\title{
Evaluation of the stiffening mechanism based on micro-sized particle inclusions in laminated composites
}

Aluizio Heleno Ribeiro Junior ${ }^{a}$, Juan Eduardo Gomez, Devin Wayne Hale, Maikson Luiz Passaia Tonatto ${ }^{c}$, Tulio Hallak Panzera ${ }^{a}$ ㅁ, Carlos Thomas ${ }^{d}$, Fabrizio Scarpa

${ }^{a}$ Centro de Inovação e Tecnologia em Materiais Compósitos - CITeC, Departamento de Mecânica Engenharia, Universidade Federal de São João del Rei-UFSJ, São João del-Rei, MG, Brasil

${ }^{b}$ Whitacre College of Engineering, Texas Tech University, United States of America

${ }^{c}$ Coordenadoria Academica, Universidade Federal de Santa Maria, Campus Cachoeira do Sul, Santa Maria, RS, Brasil

${ }^{d}$ Laboratorio de Ciencia e Ingeniería de Materiales - LADICIM, Univercidad de Cantabria, Av. Los Castros, 44, 39005, Santander, Spain

${ }^{e}$ Bristol Composites Institute - ACCIS, University of Bristol, BS8 1TR Bristol, UK

Received: January 30, 2019; Revised: May 01, 2019; Accepted: June 26, 2019

Rigid particles have been incorporated into laminated composites, especially to enhance their bending performance attributed to the stiffening of the matrix phase (i) and the increased interlaminar shear resistance (ii). In order to better evaluate the improvement mechanism provided by the particulate inclusions, this work investigates the incorporation of micro-sized silica on the top, bottom and both surfaces of glass fibre laminates, mitigating the interference of the interlocking effect. Three-point bending, and impact tests are performed to evaluate the hybrid glass fibre composites containing 5, 7.5 and $10 \mathrm{wt} \%$ of micro silica. In addition, the effect of the micro silica particles into epoxy polymers is verified under tensile, compressive and abrasion tests. A finite element model is developed to simulate the three-point bending test and to better assess the behaviour of the composite laminate. Although silica particles lead to increased compressive modulus of the epoxy polymers, their positive effect on glass fibre composites under flexural loads is more evident when placed on the bottom side of the laminates subjected to the maximum tensile stress. The incorporation of $7.5 \mathrm{wt} \%$ silica microparticles at the bottom surface of the laminates achieves higher flexural strength and lower impact resistance.

Keywords: hybrid composites, interlocking effect, micro particles, glass fibres, FEA, DoE.

\section{Introduction}

Hybrid composites consist of the combination of two different fibres and/or particles. This paper focuses on hybrid composites that combine synthetic fibres and micro-sized ceramic particles. The motivation of using micro rather than nanoparticles is the ability to spread easily over large surface areas with a constant concentration ${ }^{1-3}$. According to the literature, the incorporation of microparticles into fibrereinforced polymers (FRPs) can bring benefits to mechanical, tribological and thermal performances ${ }^{4-6}$.

The increase in the mechanical performance of FRPs obtained by the incorporation of particles can be attributed to the following mechanisms: matrix phase stiffening (i) ${ }^{7-9}$ and increased interlaminar shear resistance (ii), also namely as interlocking effect ${ }^{4,9-10}$. The efficiency of such mechanisms depends on particle characteristics, such as: size distribution, geometry, volume fraction, stiffness, strength and microstructure (porosity level and chemical reactivity). Silica macro-sized particles used in polymer mortars significantly increase durability and mechanical properties ${ }^{11}$. However, particle inclusions can cause decreased durability if the temperature increases with wear ${ }^{12-16}$.

The fracture energy is increased when the front of the crack becomes pinned by a rigid particle within the matrix

*e-mail: panzera@ufsj.edu.br phase in the interlaminar region ${ }^{7-8}$. The incorporation of rigid particles in the matrix phase makes it stiffer, affecting the stiffness of the composites ${ }^{1,7-9}$. The amount of particles is extremely important to achieve a positive effect, since a large amount can reduce the contact with the surface and hinder the adhesion condition between the layers ${ }^{3,8}$. The presence of particles in the interlaminar region of the laminate also provides increased friction under shear loads, leading to improved bending behaviour ${ }^{16-18}$. This effect can be enhanced by the functionalisation of the reinforcement phases, obtaining an additional bond by the chemical reactions ${ }^{18,19}$.

The impact behaviour of the laminates is largely dominated by the fracture mechanism between the fibres and the matrix phase. A strong interface condition leads to a brittle fracture of the fibres with a consequent reduction in impact resistance. In contrast, a significant portion of the impact energy is dissipated through the thermal energy generated by the friction in the pull-out effect of the fibre, which is more prone to weak bonding interfaces ${ }^{20-25}$. In addition, the presence of rigid particles in the composites can also affect their impact behaviour, since it makes the matrix phase stiffer and more brittle. The impact resistance behaviour of hybrid composites reinforced with microparticles is quite controversial in the literature. Some authors have reported improvements in impact resistance without losing flexural strength ${ }^{4,25,26}$. Experimental and computational 
efforts have been addressed to understand the mechanism of strengthening 4 .

When a composite is subjected to bending loads, maximum tensile and compressive efforts are generated on the bottom and upper layers, respectively. Stiffening of the matrix phase by the particle incorporation can also contribute to enhance the bending behaviour of composite materials. This phenomenon is controversial in the literature, especially when micro-sized particles are considered. An increase in flexural stiffness and a reduction in strength and toughness are commonly reported ${ }^{1,3,15,17,27,28}$. In general, the mechanisms of improvement are attributed to the stiffening of the matrix phase and the shear interlocking effect. In order to better assess such mechanism, this work investigates a hybrid composite reinforced with silica particles added only on the bottom and/or upper surfaces, mitigating the interference of the interlocking effect. Moreover, the incorporation of rigid particles into the polymer composites can improve their surface durability ${ }^{12-14}$. This effect is also verified by the characterisation of the particle reinforced matrix phase under abrasion test.

A full factorial design is performed to identify the effects of silica microparticle amounts and particle inclusion sites on flexural modulus, flexural strength and impact resistance of hybrid glass fibre reinforced composites. To further assess the findings for the hybrid composites, epoxy polymers reinforced with particles are evaluated in tensile, compression and abrasion tests. In addition, a non-linear finite element model is developed to evaluate the failure and damage of the hybrid laminate.

\section{Materials \& Methods}

\subsection{Design of experiment and fabrication}

A full factorial design $\left(3^{2}\right)$ is carried out to evaluate the effect of two factors at three levels, as follows, (i) amount of particles - $5 \mathrm{wt} \%, 7.5 \mathrm{wt} \%$, and $10 \mathrm{wt} \%$ and (ii) particle site - top, bottom and both surface layers (Figure 1), leading to 9 experimental conditions (Table 1). A non-particulate laminate is manufactured as a reference condition.

Renlam M epoxy resin and Ren HY 956 hardener (5:1 ratio) are provided by Huntsman (Brazil). The glass fibre fabric is supplied by Texiglass (Brazil). The silica microparticles are supplied by Moinhos Gerais Company (Brazil).
Table 1. Full factorial design $\left(3^{2}\right)$.

\begin{tabular}{ccc}
\hline Condition & Particle site & $\begin{array}{c}\text { Silica inclusion } \\
\text { (wt.\%) }\end{array}$ \\
\hline 1 & Top & 5 \\
2 & Top & 7.5 \\
3 & Top & 10 \\
4 & Bottom & 5 \\
5 & Bottom & 7.5 \\
6 & Bottom & 10 \\
7 & Both sides & 5 \\
8 & Both sides & 7.5 \\
9 & Both sides & 10 \\
10 & Reference & 0 \\
\hline
\end{tabular}

The silica particles are classified by sieving in a size range of 325-400 (44-37 $\mu \mathrm{m})$. Silica particles are hand mixed with the epoxy resin for 5 minutes, then the hardener is combined and mixed for another 5 minutes. Ten cross-ply fabrics of $200 \mathrm{~g} / \mathrm{m}^{2}$ are hand-lay up using a $70 \%$ matrix volume fraction to obtain $2 \mathrm{~mm}$ thick laminate as recommended by the ATSM D790 ${ }^{29}$ and ATSM D6110 ${ }^{30}$ standards for flexural and impact tests, respectively. The laminates are cured at room temperature $\left(21 \pm 1{ }^{\circ} \mathrm{C}\right.$, RH 55\%) under low vacuum $(10 \mathrm{kPa})$ at $24 \mathrm{~h}$. Two replicates are considered in the experiment. Five samples for each test and condition are fabricated, running the total of 200 specimens. The tests are performed after 15 days of curing.

Shimadzu AG-X plus test machine is used. The flexural strength and modulus are calculated based on ATSM D790 ${ }^{29}$. Samples with $50 \times 12.7 \times 2 \mathrm{~mm}^{3}$ are tested at $2 \mathrm{~mm} / \mathrm{min}$ under three-point bending. An XJJ-50 pendulum machine is used to perform the Charpy impact test. Samples with $80 \times 10 \mathrm{~mm}^{2}$ are tested according to ASTM D6110 ${ }^{30}$. Minitab 18 software is used to statistically manipulate data through Design of Experiment (DoE) and Analysis of Variance (ANOVA).

Particulate composites consisting of epoxy polymer and silica particles, at the same fraction levels as shown in Table 1, are fabricated and tested under tensile and compressive loads to better support the discussions of the first experiment. The particles are hand-mixed with epoxy polymer for 5 minutes and then placed into silicone moulds manufactured according to ASTM standards for tensile ${ }^{31}$ and compressive ${ }^{32}$ tests.

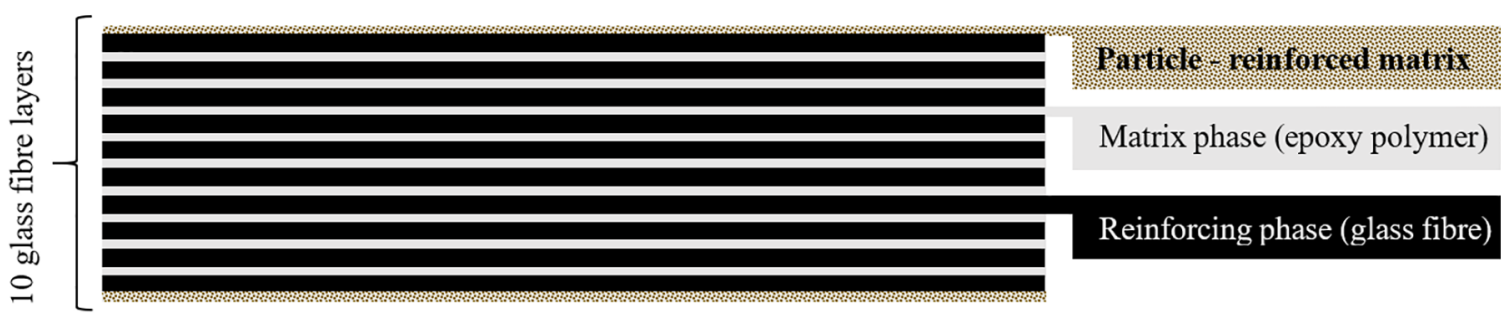

Figure 1. Illustration of the composite stacking sequence. 
In addition, an abrasion test is performed based on the recommendations of EN 14617-4 ${ }^{33}$. In this case, two experimental levels with five samples each are tested: epoxy polymer in pristine condition $(0 \mathrm{wt} \%)$ and reinforced with $7.5 \mathrm{wt} \%$ silica. Abrasive corundum with a grain size of F80 is used. The samples are fabricated via silicone mould of $10 \times 40 \times 160 \mathrm{~mm}^{3}$. Abrasion is obtained by measuring the width of the wear mark at the centre of the sample.

\subsection{Numerical simulations}

Finite element (FE) model of the particulate composite is designed using commercial Abaqus ${ }^{\mathrm{TM}} /$ Standard software. A nonlinear FE model is used to simulate three-point bending, as shown in Figure 2a. Non-linearity effects are included in the FE model to simulate damage and failure behaviour, as well as geometric and contact nonlinearities. For the nonlinear solution, the Newton-Raphson method is used with automatic time step increment. A quarter of symmetry is considered along the $\mathrm{X}$-axis and the $\mathrm{Y}$-axis. The symmetry conditions are implemented in lateral planes. In X-Y and Y-Z planes, the boundary conditions (BCs) used are $\mathrm{U}_{\mathrm{z}}=$ $\mathrm{U}_{\mathrm{rx}}=\mathrm{U}_{\mathrm{rx}}=\mathrm{U}_{\mathrm{ry}}=0$ and $\mathrm{U}_{\mathrm{x}}=\mathrm{U}_{\mathrm{ry}}=\mathrm{U}_{\mathrm{rz}}=0$, respectively. The supports are modelled as analytical surfaces. Each support is fixed by a reference point (RP). RPs are modelled using rigid body constraints and BCs are applied. The displacements and rotations in the RP of the lower support are not allowed $\left(\mathrm{U}_{\mathrm{x}}=\mathrm{U}_{\mathrm{y}}=\mathrm{U}_{\mathrm{z}}=\mathrm{U}_{\mathrm{rx}}=\mathrm{U}_{\mathrm{ry}}=\mathrm{U}_{\mathrm{rz}}=0\right)$. Displacement in the $\mathrm{y}$-direction is allowed and the other directions and rotations are restricted in the RP of the upper support $\left(\mathrm{U}_{\mathrm{x}}=\mathrm{U}_{\mathrm{z}}=\mathrm{U}_{\mathrm{rx}}\right.$ $=\mathrm{U}_{\mathrm{ry}}=\mathrm{U}_{\mathrm{rz}}=0$ ). A static step is used to simulate the threepoint bending of the structure. In the upper support (at RP) a displacement of $4 \mathrm{~mm}$ is applied to the Y-axis and the reaction force in the $\mathrm{RP}$ is monitored.

The contact between the supports and the particulate composite part is modelled using normal and tangential
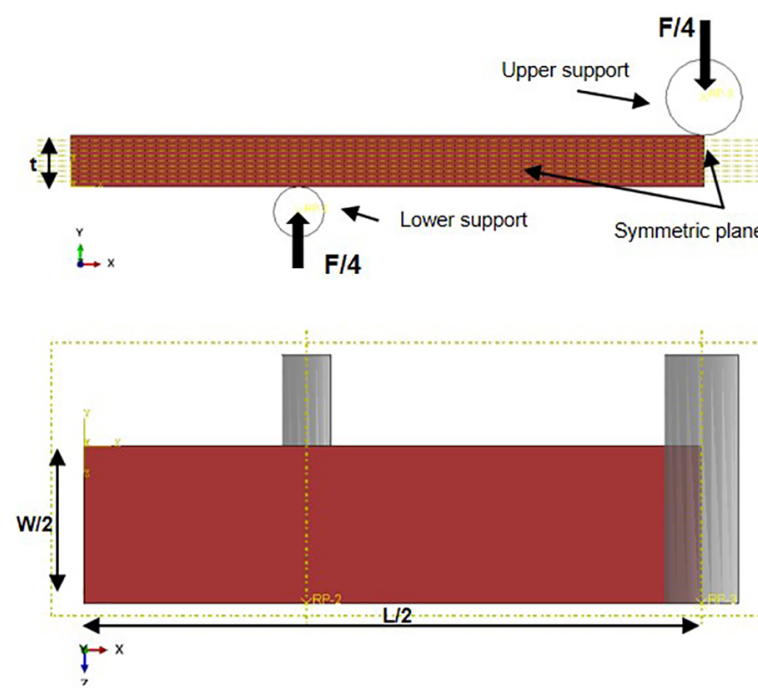

behaviour. The hard contact is used in the normal direction, while frictionless is used in the tangential direction. The particulate composite plies are meshed with $3 \mathrm{D}$ elements (C3D8), i.e. eight-node linear brick elements, while the cross-ply laminates are meshed with continuum shell elements (SC8R), i.e. eight-node quadrilateral in-plane general purpose. Mesh refinement is performed based on three-point bending loads with a convergence of 50 and 8 elements in the length and width directions, respectively, and one element per layer in the direction of thickness, as shown in Figure 2b. The modulus of elasticity and the flexural strength are calculated based on the displacement and the reaction force obtained at the reference point of the upper support.

Table 2 shows the parameters used in numerical simulations of particulate composite. The longitudinal elastic modulus $\left(\mathrm{E}_{11}\right)$, Poisson's ratio in plane 1-2 $\left(v_{12}\right)$ longitudinal tensile strength $\left(\sigma_{11}^{T}\right)$ of the glass fibre/epoxy composites are obtained from the experimental tests using the procedure of ASTM D3039 ${ }^{31}$. A $100 \mathrm{kN}$ Shimadzu testing machine equipped with video-extensometer is used to capture the axial and transverse strain at $2 \mathrm{~mm} / \mathrm{min}$ considering a set of five samples. Longitudinal compressive strength $\left(\sigma_{11}^{C}\right)$ are obtained experimentally using the procedure of ASTM D6641 ${ }^{34}$. The compressive test is performed at 1.3 $\mathrm{mm} / \mathrm{min}$. Other properties shown in Table 2 are obtained from the micromechanics analysis. The composite plies are implemented as transversally isotropic materials using engineering constants, strength, damage evolution and damage stabilisation. The damage evolution parameters and the viscosity coefficients are calibrated according to the results of the reference sample: longitudinal tensile fracture energy $\left(\mathrm{G}_{\mathrm{ITc}}=45 \mathrm{~N} / \mathrm{mm}\right)$; longitudinal compressive fracture energy $\left(\mathrm{G}_{\mathrm{ICc}}=45 \mathrm{~N} / \mathrm{mm}\right)$; transverse tensile fracture energy $\left(\mathrm{G}_{\mathrm{IITc}}=0.6 \mathrm{~N} / \mathrm{mm}\right)$; transverse compressive fracture energy

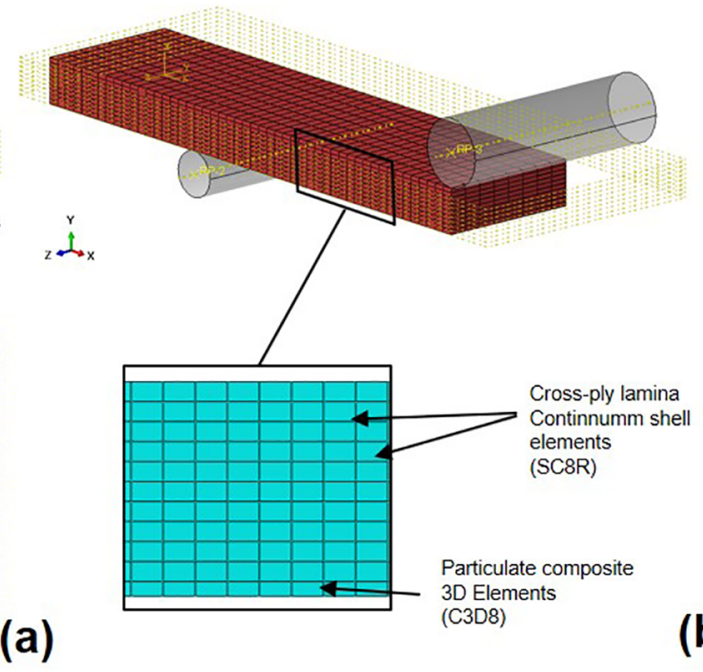

Figure 2. Three-point bending analysis of the composite laminate: (a) FE model and (b) mesh visualisation. 
Table 2. Parameters used in numerical simulations of glass fibre/epoxy composite.

\begin{tabular}{|c|c|c|c|}
\hline \multicolumn{2}{|c|}{ Material data } & Definition & Value * \\
\hline \multirow{4}{*}{ Experimental data } & $\mathrm{E}_{11}(\mathrm{GPa})$ & Longitudinal elastic modulus & $10.6 \pm 0.74$ \\
\hline & $\mathrm{v}_{12}=\mathrm{v}_{13}$ & $\begin{array}{l}\text { Poisson's ratio in planes } \\
1-2 / 1-3\end{array}$ & $0.39 \pm 0.05$ \\
\hline & $\sigma_{11}^{T}(\mathrm{MPa})$ & Longitudinal tensile strength & $224.5 \pm 11.2$ \\
\hline & $\sigma_{11}^{C}(\mathrm{MPa})$ & $\begin{array}{l}\text { Longitudinal compressive } \\
\text { strength }\end{array}$ & $113.3 \pm 9.5$ \\
\hline \multirow{8}{*}{ Micromecanical analysis } & $\mathrm{E}_{22}=\mathrm{E}_{33}(\mathrm{GPa})$ & Transverse elastic modulus & 10.6 \\
\hline & $\mathrm{v}_{23}$ & Poisson's ratio in plane 2-3 & 0.40 \\
\hline & $\mathrm{G}_{12}=\mathrm{G}_{13}(\mathrm{GPa})$ & Shear modulus & 2.7 \\
\hline & $\mathrm{G}_{23}(\mathrm{GPa})$ & $\begin{array}{l}\text { Transverse shear modulus in } \\
\text { plane } 2-3\end{array}$ & 2.9 \\
\hline & $\sigma_{22}^{T}(\mathrm{MPa})$ & Transverse tensile strength & 224.5 \\
\hline & $\sigma_{22}^{C}(\mathrm{MPa})$ & $\begin{array}{c}\text { Transverse compressive } \\
\text { strength }\end{array}$ & 113.3 \\
\hline & $\mathrm{t}_{12}=\mathrm{t}_{13}(\mathrm{MPa})$ & Shear strength in plane $1-2 / 1-3$ & 38 \\
\hline & $\mathrm{t}_{23}(\mathrm{MPa})$ & Shear strength in plane $2-3$ & 38 \\
\hline
\end{tabular}

(*) Values obtained based on experimental tests, Average \pm Standard deviation.

$\left(\mathrm{G}_{\mathrm{IICc}}=0.6 \mathrm{~N} / \mathrm{mm}\right)$; viscosity coefficient in the longitudinal compressive/tensile direction (0.001) and viscosity coefficient in the transverse compressive/tensile direction (0.005). Hashin failure criterion ${ }^{35}$ is used in the cross-ply laminate to analyse the failure of the hybrid composite. The progressive damage model is used to predict the mechanical response. Continuum damage mechanics (CDM) proposed by Lapczyk and Hurtado ${ }^{36}$ is used to evaluate the damage of the laminates. The particulate matrix phase is modelled as isotropic material and its modulus of elasticity for different silica inclusions is obtained experimentally as shown in Table 3. The Poisson's ratio of 0.35 is considered for all samples, which is obtained from the Huntsman datasheet for the Renlam M / HY 956 epoxy system. Then, the flexural strength and modulus of elasticity are calculated by same procedure described in ASTM D790 ${ }^{29}$.

\section{Results}

\subsection{Effect of silica on matrix phase}

Table 3 shows the mechanical properties of the silica microparticle-reinforced epoxy polymer. Tukey's multiple comparison test, at 95\% confidence interval, is conducted and presented in Table 3. Similar letter grouping indicates the means are statistically equivalent. The letter group classifies the means from highest to lowest starting with group A. No significant changes are evidenced for the tensile modulus $\left(\mathrm{E}_{\mathrm{T}}\right)$ response due to the same letter group $\mathrm{A}$. The tensile strength $\left(\mathrm{S}_{\mathrm{T}}\right)$ is reduced by the increase of silica particles. In contrast, the compressive modulus $\left(\mathrm{E}_{\mathrm{C}}\right)$ is increased as the amount of particle increases. The levels of $5 \mathrm{wt} \%$ and $7.5 \mathrm{wt} \%$ provide similar means shown by letter group B. Higher compressive strength $\left(\mathrm{S}_{\mathrm{C}}\right)$ is achieved when $7.5 \mathrm{wt} \%$ and $10 \mathrm{wt} \%$ silica levels are incorporated (Group A). The level of $5 \mathrm{wt} \%$ does not affect this response, since it is classified as the same letter group (B) of the reference condition. Tensile strength data are slightly decreased, while the compressive strength is increased by the incorporation of silica.

Table 4 shows the abrasion results analysed by ANOVA (one-way) and Tukey test. A P-value of 0.047 and different letter groups ( $\mathrm{A}$ and $\mathrm{B}$ ) indicate the incorporation of particles affects the tribological behaviour of the polymer. Silica reinforced polymers present $8.7 \%$ lower wear width than neat polymers, revealing a major durability against abrasion. This behaviour shows that the silica inclusions in epoxy polymer, as well as in composite laminates protect their surfaces against abrasive wear.

\subsection{Flexural and impact behaviours}

Table 5 shows the analysis of variance (ANOVA) for the mean flexural and impact data. P-values less or equal to $0.05(5 \%)$ are considered significant at a $95 \%$ confidence level. Second-order interaction effects (in bold text) are significant for all responses, as shown in Table 5 (P-values $\leq 0.05)$. $\mathrm{R}^{2}$ values close to $100 \%$ indicate well-fitted data to the statistical model.

Figure 3 shows the interaction effect plots for the mean flexural strength (a) and modulus (b). Higher values of flexural strength are obtained when silica particles are incorporated, especially in the composite bottom layer, followed by the top layer (Figure 3a). The inclusion of particles on the top surface does not provide greater flexural strength as expected, 
Table 3. Mechanical properties for particulate reinforced epoxy polymer (Tukey test).

\begin{tabular}{ccccccccc}
\hline Silica $(\mathrm{wt} \%)$ & $\mathrm{E}_{\mathrm{T}}(\mathrm{GPa})$ & Group & $\mathrm{S}_{\mathrm{T}}(\mathrm{MPa})$ & Group & $\mathrm{E}_{\mathrm{C}}(\mathrm{GPa})$ & Group & $\mathrm{S}_{\mathrm{C}}(\mathrm{MPa})$ & $\mathrm{Group}$ \\
\hline 0 & 2.05 & $\mathrm{~A}$ & 41.00 & $\mathrm{~A}$ & 2.26 & $\mathrm{C}$ & 66.72 & $\mathrm{~B}$ \\
5 & 2.01 & $\mathrm{~A}$ & 39.05 & $\mathrm{AB}$ & 2.36 & $\mathrm{~B}$ & 71.16 & $\mathrm{AB}$ \\
7.5 & 1.99 & $\mathrm{~A}$ & 37.80 & $\mathrm{~B}$ & 2.42 & $\mathrm{~B}$ & 72.32 & $\mathrm{~A}$ \\
10 & 2.20 & $\mathrm{~A}$ & 36.52 & $\mathrm{C}$ & 2.55 & $\mathrm{~A}$ & 73.63 & $\mathrm{~A}$ \\
\hline
\end{tabular}

Table 4. Abrasion test results (Tukey test).

\begin{tabular}{ccc}
\hline ANOVA & P-value $=0.047$ \\
\hline Silica (wt $\%)$ & Mean wear width (mm) & Tukey (Group) \\
0 & 17.91 & A \\
7.5 & 16.47 & B \\
\hline
\end{tabular}

Table 5. Analysis of Variance.

\begin{tabular}{cccc}
\hline \multirow{2}{*}{ Experimental factor } & \multicolumn{3}{c}{ P-value $\leq 0.05$} \\
\cline { 2 - 4 } & Flexural Strength & Flexural Modulus & Impact Strength \\
\hline Percent & 0.045 & 0.000 & 0.000 \\
Position & 0.000 & 0.000 & 0.000 \\
Percent*Position & $\mathbf{0 . 0 3 0}$ & $\mathbf{0 . 0 0 3}$ & $\mathbf{0 . 0 1 4}$ \\
R2-adjusted (\%) & $\underline{98.86 \%}$ & $\underline{96.96 \%}$ & $\underline{98.97 \%}$ \\
\hline
\end{tabular}

as revealed by the particulate composite results previously shown in Table 3. It is noteworthy that the inclusion of particles on both sides leads to the reduction of strength compared to the reference condition. In general, the amount of silica does not substantially change the strength of the composites. In contrast, a silica level of $7.5 \mathrm{wt} \%$ gives higher stiffness values for all inclusion sites (Figure 3b). The highest flexural modulus is achieved when $7.5 \mathrm{wt} \%$ of silica is added to the bottom layer of the laminate. The hybrid composites only reach an elastic modulus higher than the reference condition when fabricated with $7.5 \mathrm{wt} \%$ of silica placed in the lower or upper layers of the laminate. This finding indicates that the interlocking effect, achieved by the particles in the interlaminar region, plays an important role in the stiffening and strengthening of hybrid composites, as reported in the literature ${ }^{1-4,7-9,9,16,18,22-23}$.

It is well known that the bending load combines tensile (bottom beam side), compressive (upper beam side) and shear loadings ${ }^{1}$. In this work, no interlocking effect in the interlaminar region is considered, since the particles are incorporated upon the surfaces of the laminate. Considering the findings for the reinforced matrix phase shown in Table 3 , it was expected that the samples reinforced on the top surface (under compressive loads) would achieve higher bending performance. However, higher strength $(13.6 \%)$ and modulus $(16 \%)$ are achieved when the particles are placed on the bottom surface, which is under tensile stress (Figure 3 ). The presence of particles on only one beam side can modify the moment of inertia of area affecting the distribution of the shear and normal loads generated by the bending.
This effect is better assessed through the FEA presented later. The presence of silica on the bottom surface may also contribute to delay the propagation of the crack, as reported in the open literature ${ }^{1,16,18}$. It is noteworthy that the incorporation of particles in the two composite layers (TB) leads to a lower bending behaviour (Figure 3 ) in relation to the reference condition. This result also implies that the shear bonding effect provided by the particles in the interlaminar region is relevant to improve the flexural performance of hybrid composites.

Table 6 shows the numerical and experimental data comparison for bending behaviour. The numerical model cannot identify all the effects found in the experimental tests. However, good agreement is found between the two methods. The maximum difference obtained for the flexural strength is $20.3 \%$ when the composites are made with $5 \mathrm{wt} \%$ of silica on the bottom layer. The maximum difference found for the flexural modulus is $21.7 \%$ when laminates are made with $10 \mathrm{wt} \%$ of silica placed on both sides. The numerical model demonstrates that the maximum flexural strength occurs when silica is placed in the top layer of the laminate. This behaviour is attributed to the mechanical properties of the silica reinforced epoxy polymer. The minimum flexural strength is found when silica is placed on both sides. A minimal difference between the numerical model and experiments is also found for this condition, being attributed to the lower strength of the silica reinforced epoxy polymer compared to the glass fibre/epoxy laminate.

The FE model was not able to predict the variations in flexural strength caused by shear loads ${ }^{16}$ and the interlocking effect ${ }^{4}$. 

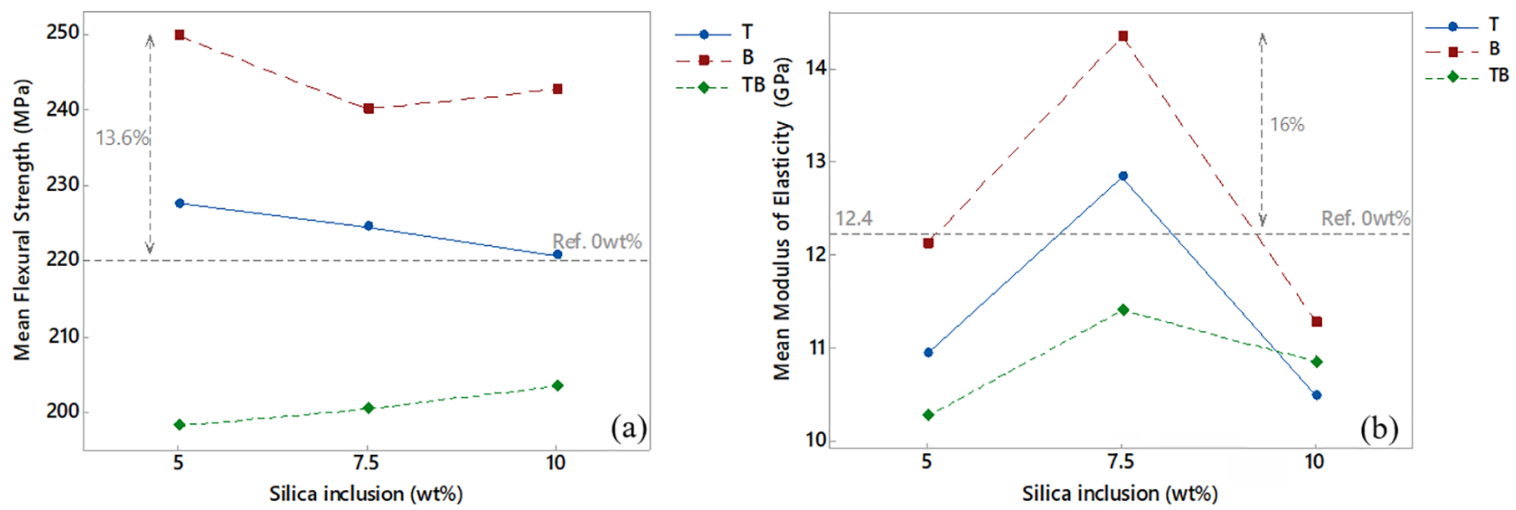

Figure 3. Interaction effect plots for mean flexural (a) strength and (b) modulus.

Table 6. Numerical and experimental flexural behaviour.

\begin{tabular}{|c|c|c|c|c|c|c|c|c|c|c|c|}
\hline \multirow{2}{*}{\multicolumn{2}{|c|}{ Mechanical properties }} & \multirow{3}{*}{$\begin{array}{l}\text { Ref. } \\
219.9\end{array}$} & \multicolumn{3}{|c|}{ Bottom (wt $\%)$} & \multicolumn{3}{|c|}{ Top (wt $\%)$} & \multicolumn{3}{|c|}{ Both sides (wt $\%)$} \\
\hline & & & 5 & 7.5 & 10 & 5 & 7.5 & 10 & 5 & 7.5 & 10 \\
\hline \multirow{2}{*}{$\begin{array}{c}\text { Flexural } \\
\text { strength } \\
(\mathrm{MPa})\end{array}$} & Numerical & & 196.1 & 195.4 & 195.6 & 213.2 & 213.3 & 214.0 & 196.8 & 196.2 & 196.4 \\
\hline & Experimental & 220.0 & 246.0 & 241.0 & 244.0 & 228.0 & 226.4 & 221.0 & 198.5 & 201.7 & 204.0 \\
\hline \multicolumn{2}{|c|}{ Difference (\%) } & -0.1 & -20.3 & -18.9 & -19.9 & -6.5 & -5.8 & -3.2 & -0.8 & -2.7 & -3.7 \\
\hline \multirow{2}{*}{$\begin{array}{c}\text { Modulus of } \\
\text { elasticity } \\
\text { (GPa) }\end{array}$} & Numerical & 12.42 & 10.86 & 10.86 & 10.91 & 10.89 & 10.90 & 10.78 & 9.21 & 9.22 & 9.28 \\
\hline & Experimental & 12.40 & 12.14 & 14.07 & 11.41 & 10.90 & 12.79 & 10.50 & 10.27 & 11.40 & 11.86 \\
\hline \multicolumn{2}{|c|}{ Difference $(\%)$} & 0.2 & -10.5 & -22.8 & -4.4 & -0.1 & -14.7 & 2.7 & -10.3 & -19.1 & -21.7 \\
\hline
\end{tabular}

However, FE model demonstrates that the effect of particle inclusions on the longitudinal stress of the laminates. Figure 4 shows the effect of longitudinal stress along the thickness of the laminate considering $20 \%$ of the maximum displacement. Lower stresses are observed in the region of the particle-reinforced matrix phase due to its lower modulus of elasticity compared to the laminate. The reference condition and the reinforcing samples on both sides demonstrate zero stress closer to the centre of the laminate (depth $0 \mathrm{~mm}$ ) when compared to the other samples due to the symmetry of these laminates. Reinforced composites on the top side exhibit higher compressive stresses above the neutral axis when compared to the bottom silica sample. In contrast, the bottom-silica sample exhibits higher tensile stresses below the neutral line. This effect may have contributed to the reinforcing effect when the particles are placed on the lower beam side, which presents higher strength, due to its lower compressive strength of glass/epoxy laminate compared to the tensile strength. In addition, the presence of silica on the top of bottom surfaces modifies the centre of gravity of the sample cross section, affecting the stress distribution of the laminate.

The presence of particles on the top or bottom sides leads to an unbalance mass, dislocating the centre of gravity and the neutral axis $\left(\mathrm{y}_{1}<\mathrm{y}<\mathrm{y}_{2}\right)$ of the cross section (Figure 5). When the particles are incorporated on the bottom surface (Figure $5 \mathrm{a})$, the centre of gravity is lower $\left(\mathrm{y}_{1}<\mathrm{y}\right)$, which

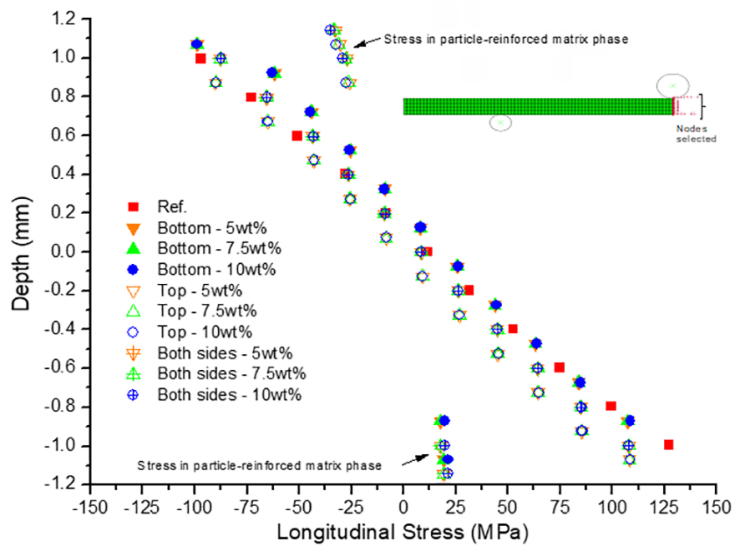

Figure 4. Depth vs. longitudinal stress curves for the hybrid composite laminates.

increases the area of the section under compressive loads when subjected to bending. An opposite behaviour is obtained when the particles are added to the top beam side (Figure $5 b)$. It is well known that the matrix phase is responsible for the compressive loads while the fibres withstand the tensile loadings. In this case, the inclusion of particles on the bottom surface is more favourable because they strengthen the upper beam side by increasing the compressive area, as previously revealed by the FEA, i.e. a higher level of stress in the regions where the particles are incorporated. 

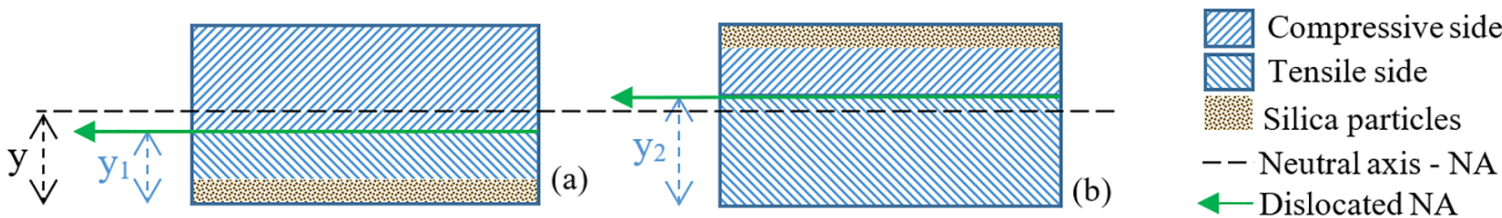

Figure 5. Scheme to illustrate the effect of silica particles on the neutral axis of unbalanced mass laminates with particles placed on the bottom side (a) and on the top side (b).

Figure 6 shows the plot of the interaction effect for the mean impact resistance. The impact performance reveals an opposite behaviour in relation to the bending test since the inclusion of particles makes the composites stiffer, consequently absorbing less amount of energy under a dynamic load. It is noted that the reference condition (without particles) achieves the highest impact resistance at $135 \mathrm{~kJ} /$ $\mathrm{m}^{2}$. A significant reduction $(62 \%)$ in impact resistance is evidenced by laminates made with $7.5 \mathrm{wt} \%$ silica on the bottom surface. Cao and Cameron ${ }^{4}$ reported positive effects on impact response by adding micro particles in the interlaminar region of glass fibre composites attributed to the presence of fibre pull-out mechanism and increased interlocking effect. The results presented here also corroborate to confirm that the increased interlaminar shear resistance caused by particle inclusions plays an important role in the impact behaviour of hybrid laminates.

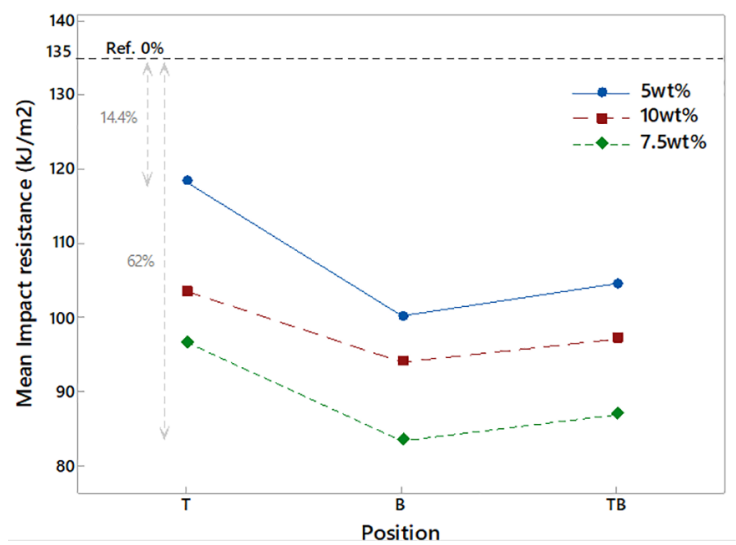

Figure 6. Interaction effect plot for mean impact resistance.

\section{Conclusion}

A glass fibre laminate and a polymer reinforced with silica particles are evaluated. The main conclusions are following described:

- The inclusion of silica particles in the epoxy polymer leads to the increase of the compressive modulus (2.53 GPa), compressive strength ( $73.60 \mathrm{MPa})$ and abrasion wear resistance. However, no substantial change is verified for the tensile behaviour.

- Particles on both sides of glass fibre composites leads to reduced flexural strength and stiffness compared to the reference condition.
- Glass fibre hybrid composites only reach a modulus larger than the reference condition (without particles) when fabricated with $7.5 \mathrm{wt} \%$ silica on the bottom or top sides of the laminate.

- The incorporation of $7.5 \mathrm{wt} \%$ silica microparticles on the bottom surface of the laminates results in higher bending behaviour and lower impact resistance.

- The highest impact resistance $\left(135 \mathrm{~kJ} / \mathrm{m}^{2}\right)$ is achieved by the reference condition (without particles), followed by hybrid laminates made with $5 \mathrm{wt} \%$ of particles added on the top surface.

- Anon-linear FE model is developed to evaluate the failure and damage of the hybrid laminate. A good agreement between numerical and experimental results is found for flexural behaviour.

- FE model reveals that the higher flexural strength achieved by the incorporation of silica on the lower beam side modifies the stress distribution of laminate. The lower compressive stress is found for silica on the lower beam side, being attributed to the lower neutral axis. The lower compressive strength of glass/epoxy laminate when compared to tensile strength may be contributed to this behaviour.

- The findings imply that the shear bonding effect provided by the particles in the interlaminar region is relevant to improve the flexural and impact performance of hybrid composites, as reported in the literature.

\section{Acknowledgements}

The authors would like to thank Texas Tech University, CNPq (PDE -205255/2017-5) and FAPEMIG (PPM-0007517) for the financial support provided.

\section{References}

1. Santos JC, Machado LVG, Panzera TH, Schiavon MA, Christoforo AL, Scarpa F. Hybrid glass fibre reinforced composites with micro and poly-diallyldimethylammonium chloride (PDDA) functionalized nano silica inclusions. Materials and Design. 2015;65:543-549. Available from: https://doi.org/10.1016/j. matdes.2014.09.052

2. Cao Y, Cameron J. The effect of curing conditions on the properties of silica modified glass fiber reinforced epoxy composite. Journal of Reinforced Plastics and Composites. $2007 \mathrm{Jan} ; 26(1): 41-50$. Available from: https://doi.org/10.1177/0731684407069950 
3. Ribeiro Filho SLM, Oliveira PR, Vieira LMG, Panzera TH, Freire RTS, Scarpa F. Hybrid bio-composites reinforced with sisal-glass fibres and Portland cement particles: A statistical approach. Composites Part B: Engineering. 2018;149:58-65. Available from: https://doi.org/10.1016/j.compositesb.2018.05.019

4. Cao Y, Cameron J. Impact properties of silica particle modified glass fibre reinforced epoxy composite. Journal of Reinforced Plastics and Composites. 2006 May;25(7):761-769. Available from: https://doi.org/10.1177/0731684406063536

5. Chandrasekaran VCS, Advani SG, Santare MH. Role of processing on interlaminar shear strength enhancement of epoxy/ glass fiber/multi-walled carbon nanotube hybrid composites. Carbon. 2010 Nov;48(13):3692-3699. Available from: https:// doi.org/10.1016/j.carbon.2010.06.010

6. Jang JS, Varischetti J, Lee GW, Suhr J. Experimental and analytical investigation of mechanical damping and CTE of both $\mathrm{SiO}_{2}$ particle and carbon nanofiber reinforced hybrid epoxy composites. Composites Part A: Applied Science and Manufacturing. 2011 Jan;42(1):98-103. Available from: https:// doi.org/10.1016/j.compositesa.2010.10.008

7. Jesson DA, Watts JF. The interface and interphase in polymer matrix composites: effect on mechanical properties and methods for identification. Polymer Reviews. 2012 Sep;52(3):321-354. Available from: https://doi.org/10.1080/15583724.2012.710 288

8. Silva LJ, Panzera TH, Velloso VR, Rubio JCC, Christoforo AL, Scarpa F. Statistical design of polymeric composites reinforced with banana fibres and silica microparticles. Journal of Composite Materials. 2012 May;47(10):1199-210. Available from: https://doi.org/10.1177/0021998312446499

9. Kistaiah N, Kiran CU, Reddy GR, Rao MS. Mechanical characterization of hybrid composites: A review. Journal of Reinforced Plastics and Composites. 2014;33(14):1364-1372. Available from: https://doi.org/10.1177/0731684413513050

10. Zeng Y, Liu HY, Mai YW, Du XS. Improving interlaminar fracture toughness of carbon fibre/epoxy laminates by incorporation of nano-particles. Composites Part B: Engineering. 2012 Jan;43(1):90-94. Available from: https://doi.org/10.1016/j. compositesb.2011.04.036

11. Thomas C, Lombillo I, Polanco JA, Villegas L, Setién J, Biezma MV. Polymeric and cementitious mortars for the reconstruction of natural stone structures exposed to marine environments. Composites Part B: Engineering. 2010 Dec;41(8):663-672. Available from: https://doi.org/10.1016/j.compositesb.2010.08.007

12. Martuscelli CC, Santos JC, Oliveira PR, Panzera TH, Aguilar MTP, Garcia CT. Polymer-cementitious composites containing recycled rubber particles. Construction and Building Materials. 2018 May;170:446-454. Available from: https:// doi.org/10.1016/j.conbuildmat.2018.03.017

13. Thomas C, Borges PHR, Panzera TH, Cimentada A, Lombillo I. Epoxy composites containing CFRP powder wastes. Composites Part B: Engineering. 2014 Mar;59:260-268. Available from: https://doi.org/10.1016/j.compositesb.2013.12.013
14. Thomas C, Cimentada A, Diego S, Casado JA, Carrascal IA. Mechanical and physical properties of epoxy composites containing CFRP powder wastes. In: 16th European Conference on Composite Materials; 2014 Jun 22-26; Seville, Spain: ECCM16; 2014.

15. Li M, Gu Y, Liu Y, Li Y, Zhang Z. Interfacial improvement of carbon fiber/epoxy composites using a simple process for depositing commercially functionalized carbon nanotubes on the fibers. Carbon. 2013 Feb; 52:109-121. Available from: https://doi.org/10.1016/j.carbon.2012.09.011

16. Torres RB, Santos JC, Panzera TH, Christoforo AL, Borges PHR, Scarpa F. Hybrid glass fibre reinforced composites containing silica and cement microparticles based on a design of experiment. Polymer Testing. 2017 Feb; 57:87-93. Available from: https://doi.org/10.1016/j.polymertesting.2016.11.012

17. Haque A, Shamsuzzoha M, et al. S2-glass/epoxy polymer nanocomposites: manufacturing. structures. thermal and mechanical properties. Journal of Composite Materials. 2003 Oct;37(20):1821-37. Available from: https://doi. org/10.1177/002199803035186

18. Detomi AC, Santos RM, Ribeiro Filho SLM, Martuscelli CC, Panzera TH, Scarpa F. Statistical effects of using ceramic particles in glass fibre reinforced composites. Materials and Design. 2014 Mar;55:463-470. Available from: https://doi. org/10.1016/j.matdes.2013.09.026

19. Ramanathan T, Bismarck A, Schulz E, Subramanian K. Investigation of the influence of surface activated carbon fibres on debonding energy and frictional stress in polymer-matrix composites by the micro-indentation technique. Composites Science and Technology. 2011 Dec;61(16):2511-2518. Available from: https://doi.org/10.1016/S0266-3538(01)00169-5

20. Jang J, Yang H. The effect of surface treatment on the performance improvement of carbon fiber/polybenzoxazine composites. Journal of Materials Science. 2000 May;35(9):2297-2303. Available from: https://doi.org/10.1023/A:1004791313979

21. Albuquerque AC, Joseph K, Carvalho LH, d'Almeida JRM. Effect of wettability and ageing conditions on the physical and mechanical properties of uniaxially oriented jute-rovingreinforced polyester composites. Composites and Science Technology. 2000 May;60(6):833-844. Available from: https:// doi.org/10.1016/S0266-3538(99)00188-8

22. Oliveira LA, Santos JC, Panzera TH, Freire RTS, Vieira LMG, Scarpa F. Evaluation of hybrid-short-coir-fibre-reinforced composites via full factorial design. Composite Structures. 2018 Oct;202:313-323. Available from: https://doi.org/10.1016/j.compstruct.2018.01.088

23. Santos JC, Vieira LMG, Panzera TH, Freire RTS, Christoforo AL, Scarpa F. Impact behaviour of hybrid carbon fibre composites reinforced with silica micro- and functionalized nanoparticles. Nano Hybrids and Composites. 2018 Jun;21:1-9. Available from: https://doi.org/10.4028/www.scientific.net/NHC.21.1

24. Rahmanian S, Thean KS, Suraya AR, Shazed MA, Salleh MAM, Yusoff HM. Carbon and glass hierarchical fibers: Influence of carbon nanotubes on tensile flexural and impact properties of short fiber reinforced composites. Materials and Design. 2013 Jan;43:10-16. Available from: https://doi.org/10.1016/j.matdes.2012.06.025 
25. Gokuldass R, Ramesh R. Mechanical and low velocity impact behaviour of intra-ply glass/kevlar fibre reinforced nano-silica and micro-rubber modified epoxy resin hybrid composite. Materials Research Express. 2019 Feb;6(5):055302. Available from: https://doi.org/10.1088/2053-1591/aaff1e

26. Dassios KG. A review of the pull-out mechanism in the fracture of brittle- matrix fibre-reinforced composites. Advanced Composites Letters. 2007 Jan;16(1):17-24.

27. Silva LJ, Panzera TH, Christoforo AL, Rubio JCC, Scarpa F. Micromechanical analysis of hybrid composites reinforced with unidirectional natural fibres. silica microparticles and maleic anhydride. Materials Research. 2012 Dec;15(6):1003-1012. Available from: https://doi.org/10.1590/S1516-14392012005000134

28. Melo ABL, Panzera TH, Freire RTS, Scarpa F. The effect of Portland cement inclusions in hybrid glass fibre reinforced composites based on a full factorial design. Composite Structures. 2018 Oct;202:233-240. Available from: https://doi.org/10.1016/j.compstruct.2018.01.069

29. American Society for Testing and Materials (ASTM). D790-03 Standard - Test Methods for Flexural Properties of Unreinforced and Reinforced Plastics and Electrical Insulating Materials. West Conshohocken, PA: ASTM International; 2015.

30. American Society for Testing and Materials (ASTM). D611010 - Standard Test Method for Determining the Charpy Impact Resistance of Notched Specimens of Plastics. West Conshohocken, PA: ASTM International; 2010.
31. American Society for Testing and Materials (ASTM). D303914 - Standard Test Method for Tensile Properties of Polymer Matrix Composite Materials. West Conshohocken, PA: ASTM International; 2014.

32. American Society for Testing and Materials (ASTM). D69515 - Standard Test Method for Compressive Properties of Rigid Plastics. West Conshohocken, PA: ASTM International; 2015.

33. The National Standards Authorithy of Ireland (NSAI). EN 14617 4. Agglomerated stone - Test methods - Part 4: Determination of the abrasion resistance. Brussels: European Committee for Standardization; 2012.

34. American Society for Testing and Materials (ASTM). D6641 / D6641M-16e1 - Standard Test Method for Compressive Properties of Polymer Matrix Composite Materials Using a Combined Loading Compression (CLC) Test Fixture. West Conshohocken, PA: ASTM International; 2016.

35. Hashin Z. Fatigue Failure Criteria for Unidirectional Fiber Composites. Journal of Applied Mechanics. 1980 Dec;47(4):846852. Available from: https://doi.org/10.1115/1.3157744

36. Lapczyk I, Hurtado JA. Progressive damage modeling in fiberreinforced materials. Composites Part A: Applied Science and Manufacturing. 2007 Nov;38(11):2333-2341. Available from: https://doi.org/10.1016/j.compositesa.2007.01.017 